\title{
Jacqui Briggs EPS Prize 2019
}

(c) European Consortium for Political Research 2020

Congratulations to the winning article of the Jacqui Briggs EPS Prize 2019: Stuart Brown, "Britain's EU referendum: How did political science rise to the challenge? An assessment of online contributions during the campaign." (EPS, Vol. 18, No. 1, 2019).

In their assessment, the judges summarized the benefits of the article as follows:

"As new media offer political scientists increasing opportunities to engage in public discourse, Stuart Brown provides a timely and highly relevant piece evaluating the contributions of political scientists to the BREXIT referendum in Britain. Brown finds that academics are faced with two competing pressures in their public engagement. On the one hand, positional content supporting one side of a highly polarized debate generates greater public interest; on the other, the value of academic contributions to public discourse is in their credibility, which is tied to the perception of political scientists as 'fair-minded observers' making 'evidence-based contributions.' Brown cautions political scientists tempted by the siren song of likes and page views to void conflating popularity of content with the value of content. Instead, Brown challenges us to consider the long-term impact of each contribution, and to value works offering enduring insights over positional pieces that are quickly shared but quickly forgotten."

The prize committee was comprised of:

Charity Butcher, Kennesaw State University (chair)

Silvia Erzeel, Vrije Universiteit Brussel

Christopher Pallas, Kennesaw State University

Publisher's Note Springer Nature remains neutral with regard to jurisdictional claims in published maps and institutional affiliations. 